\title{
Correlations between pupil size and the semantic differential: An experimental paradigm and pilot study
}

BARRY E. COLLINS, UNIVERSITY OF CALIFORNIA, LOS ANGELES, PHOEBE C. ELLSWORTH, STANFORD UNIVERSITY ROBERT L. HELMREICH, UNIVERSITY OF TEXAS AT AUSTIN

Both changes in pupil size and ratings on the three dimensions of the semantic differential were obtained in response to 36 stimuli. Correlations were computed across stimuli for each subject. These within-subject correlations between changes in pupil size and the scales of the semantic differential indicated a positive relationship between pupil size and the "potency" scale (strong-weak; large-small; heavylight) of the semantic differential. Contrary to an extrapolation of Hess' discussions, there is no evidence that pupil size is positively related to the evaluative (good-bad) dimension of meaning. No results were obtained for verbal, attitudestatement stimuli.

Hess and his colleagues (Hess \& Polt, 1960, 1964; Hess, 1965; Hess, Seltzer, \& Schlien, 1965) have suggested that changes in pupil size may have a different and greater significance as a psychological variable than has previously been recognized. According to Hess, "The evidence suggests that at least with respect to visual material there is a continuum of responses that range from extreme dilation for interesting or pleasing stimuli to extreme constriction for material that is unpleasant or distasteful to the viewer" (1965, p. 50). As the authors interpret Hess-especially his discussion of pupil dilation when Ss were exposed to pictures of a preferred political candidate $(1965$, p. 53)-he seems to be saying that pupil size should be correlated with the evaluative or "good-bad" dimension of the semantic differential (Osgood, Sucl, \& Tannenbaum, 1957).

Hess' typical technique is to use a limited set of stimuli (e.g., pictures of Johnson vs Goldwater or nude females vs males). Even though a priori notions about differential interest may be verified by verbal ratings, any given pair of stimuli may differ on dimensions other than interest value. It is possible to argue that the dilation is in response to one of the additional dimensions of difference (e.g., brightness, threat, etc.) rather than interest value. A correlational analysis with a $\mathrm{N}$ of stimuli would be useful, because irrelevant dimensions would have to affect both dilation and verbal ratings in order to produce a correlation. Brightness and order of artifacts, for instance, would have to affect both dilation and the verbal ratings in order to produce an artifactual correlation between the two variables.

Method

The present study recorded both changes in pupil size and semantic differential ratings (Osgood et al, 1957) evoked by the same set of stimuli. Fourteen polar adjective pairs were used in the present study covering the three defined dimensions of attitude: the evaluative dimension, the activity dimension, and the potency dimension. There were eight pairs of evaluative adjectives: good-bad, clean-dirty, sweetsour, pleasant-unpleasant, fragrant-foul, beautifulugly, nice-awful, and sacred-profane. There were three pairs of adjectives in the activity scale: activepassive, sharp-dull, and fast-slow; and three pairs in the potency scale: strong-weak, large-small, and heavy-light.

Eight Yale undergraduates recruited by an advertisement in the local campus newspaper were offered two dollars an hour to "look at pictures." The camera was mounted in $\dot{a}$ wooden box $18 \mathrm{in.} \mathrm{directly} \mathrm{in} \mathrm{front}$ of the $S$ and beneath his line of vision. The S's face was illuminated by a two-bulb (15 W each) standard fluorescent desk lamp mounted directly beneath the camera box. The stimuli were placed in a holder immediately above the camera lens and directly in the S's line of vision. A constant 18 in. distance between $S$ and camera was maintained. The S's field of vision contained the stimulus, the camera box, the lamp, and the solid frame.

Ten stimuli (seven verbal, three pictorial) were concerned with the draft and compulsory military service, 11 (seven verbal, four pictorial) with miscegenation, and 11 (seven verbal, four pictorial) with Yale University parietal hours. Examples of verbal stimuli are: "The years spent in the armed services are wasted"; "Negroes and whites should intermarry whenever they want to"; "Extending parietal hours would interfere with studying." Pictorial stimuli included drawings and photographs: a photograph of soldiers drilling; a drawing of a Negro man and a white woman holding hands; a photograph of a Yale undergraduate dormitory party labelled "3:00 AM" etc. There were also four "abstract art" stimulus pictures.

Each $S$ was seated so that his eyes would be centered in the photographic field. The $S$ focused on a control stimulus-a large figure " 5 " printed on a white card. When he indicated he was ready, his eyes were photographed for $8 \mathrm{sec}$ (16 frames) while he was looking at the control stimulus. The first experimental stimulus was then slipped into the holder so that it completely obscured the control figure "5." The experimental stimulus was then left in place for $10 \mathrm{sec}$ (20 frames). This process, including the 
$8 \mathrm{sec}$ of control filming while the $\mathrm{S}$ fixated on the figure "5," was repeated for each stimulus. The same random stimulus order was used for all Ss. Thus, for each of the 36 experimental stimuli, the $E$ obtained film records of the change in pupil size that occurred from the standard control figure " 5 " to the experimental stimulus, as well as ratings on the semantic differential scale.

\section{Results and Discussion}

Data were avallable for 33 to 36 stimuli per S.2 A separate correlation between change in pupil size and semantic differential rating was computed for each $S$. These correlations were then pooled or averaged over the eight $\mathrm{Ss}$ in order to generate a pooled within-class correlational coefficient (Winer, 1962 , p. 604) where each $\mathrm{S}$ defines a class. The only significant correlation between change in pupil size and verbal ratings in response to a stimulus occurred for the potency scale, and that only in response to pictorial stimuli. Those pictorial stimuli rated as being more potent were associated with greater pupil dilation. The pooled within-class correlation of .31 represents a weighted average of the eight correlations computed for each $S$. All eight were positive $(.62, .61, .22, .35, .46, .11, .16, .34)$ and two are significant individually at the .05 level. Eight out of eight random correlations will be of like sign only eight times in a thousand $(p=.008)$; the general pattern is far more positive than might be expected by chance. The potency-dilation correlation occurred only for the pictorial stimuli; the pooled within-class correlation for the written stimuli was only -.02.

Contrary to the authors' extrapolation of Hess' discussion, the evaluative dimension was not related to changes in pupil size. (Pooled within-class $r=-.05$ for pictorial and .01 for written stimuli.) None of the eight individual correlations are significant at the .05 level. Furthermore, the trend (six out of eight negative) is opposite to that predicted on the basis of Hess' writings. This pattern is replicated in all of the subject areas-greater dilation in response to stimuli rated as potent.

The relative luminance of the 11 pictorial stimuli was estimated by measuring the light reflected under constant illumination by a General Electric DW-48 reflected light meter. There is the expected tendency for greater dilation to occur in response to the darker stimuli-even with the restricted range of luminance represented by the 11 pictorial stimuli ( $r=-.55$ with .63 required for the .05 level when $\mathrm{df}$ $=9$ ). There is, however, clearly no consensus among Ss that the darkest pictures were rated most potent. The correlation between reflected light and potency was -.09 . There is no evidence, then, that luminance was a common third variable producing the correlation between dilation and potency. 3

In conclusion, the potency dimension was positively related to changes in pupil size. The evaluative dimension, however, was not related to changes in pupil size. Results were obtained for pictorial stimuli and not for verbal attitude statements. While not totally compatible with Hess' interpretation, these results are not necessarily inconsistent with his data. "Pin-up" pictures and favored political candidates may produce increased pupil size because they are potent (strong, large, and heavy). Hess' finding that several announced Johnson supporters at the University of Chicago increased their pupil size in response to a Goldwater picture might not have "indicated that...these people actually have a slightly more positive attitude toward Goldwater than toward Johnson" (Hess, 1965, p. 53). Rather, it may mean simply that they felt Goldwater was a potent figure. If the present data can be extrapolated, the fact that announced Johnson supporters gave Goldwater a negative evaluation (bad, dirty, sour, unpleasant, foul, ugly, awful, and profane) would not have had any effect on their pupil size. The evaluative scale, it will be remembered, is uncorrelated with the other two scales.

\section{References}

HESS, E. H. Attitude and pupil size. Scient. American, 1965, 212, 46-54. HESS, E. H., \& POLT, J. M. Pupil size as related to interest value of visual stimuli..Science, 1960, 132, 349-350.

HESS, E. H., \& POLT, J. M. Pupil size in relation to mental activity during simple problem solving. Science, 1964, 143, 1190-1192.

HESS, E. H., SELTZER, A. L., \& SHLIEN, J. M. Pupil response of hetero-and homosexual males to pictures of men and women: A pilot study. J. abnorm. Psychol 1965, 70, 165-168.

OSGOOD, C. E., SUCI, G. J., \& TANNENBAUM, P. H. The measurement of meaning. Urbana: University of Illinois Press, 1957.

WINER, B. J. Statistical principles in experimental design. New York: McGraw-Hill Book Company, 1962.

Notes

1. This research was supported by National Science Foundation grant NSF GS 492 and GS 1194 to the senior author. Thanks are extended to William Kessen who courteously looked the other way while we moonlighted his facilities.

2. Occasional technical problems with blurred film or temporary camera problems resulted in the loss of information on a few stimuli. 3. Unfortunately, there was a significant trend toward a negative correlation between potency and initial control or pretest dilation scores (within-class $r=-.24$ ). S fixated on the same control stimulus prior to being exposed to each experimental stimulus. Since he had no foreknowledge of the experimental stimulus while fixating on the control stimulus, any variation in the initial diameter scores can be regarded as random error-just as variations in the pretest are considered random in a pretest-posttest design. The correlation between initial score and potency does not account for the obtained correlation between change in diameter and potency. The correlation between potency and change remains even when the correlation between initial position and potency is partialed out. All eight partial correlations remain positive, and one is significant at the .05 level. 